\title{
A Comparison of Spanish Second Language Acquisition in Two Different Learning Contexts: Study Abroad and the Domestic Classroom
}

\author{
Norma n S e g a I o w i t z \\ Concordia University, Montréal
}

B a $\mathbf{r}$ b a $\mathbf{r}$ a $\mathbf{r}$ e e d

Carnegie Mellon University

J o e colle ntine

Northern Arizona University

B a $r$ b a $r$ a $L$ a f for

Arizona State University

\author{
Nicole Lazar \\ Carnegie Mellon University
}

\section{Ma n u I Díaz-C a mpos \\ Indiana University}

In this paper, we report the results of a study that compared differences in the linguistic gains made by native English-speaking students from the United States who were studying Spanish in one of two different contexts of learning. One was a regular university classroom situation in Colorado; the other was a study abroad program in Alicante, Spain. We examined the gains students made on a number of linguistic dimensions: oral proficiency, oral fluency, grammar, vocabulary, pronunciation, and communication strategies. In addition, we investigated the relationships between these variables and a variety of background factors, including aspects of language learning readiness. As far as we know, this is the first study to examine such a comprehensive array of variables associated with linguistic performance as a function of context of learning. Each of the individual studies that contributed to the full report of 
this project can be found in a special issue of the journal Studies in Second Language Acquisition edited by Collentine and Freed (2004). When those studies are looked at as a whole, they lead to general interpretations that were not immediately apparent when considering each of the reports separately. In this paper we review these results, discuss the larger picture that emerges, and speculate on future questions about the effects of the study abroad experience on second language acquisition (see also Freed, Segalowitz \& Dewey, 2004, for a related study).

The goals of the original investigation were to address the following three questions:

1. How did the linguistic gains made by students from the United States in a study abroad program in Spain compare to those who remained in a regular academic classroom setting at home in the United States?

2. Were there specific predictors of success for learners in these two contexts of learning?

3. What was the impact of the special environmental factors normally associated with the study abroad context, such as housing (home stays), increased opportunity for out-of-class contact, etc.?

Serious explorations of the linguistic impact of study abroad experiences began to emerge in the early 1990s, although some articles on the topic appeared during the previous decade. The most comprehensive published summaries of this research have appeared in Coleman (1998) and Freed (1995a, 1998). Interest in this topic has been generated both by scholars eager to explore the influence of the context of learning on second language acquisition and by program organizers and government agencies concerned with the need for rigorous empirical documentation of the longstanding belief in the linguistic benefits of study abroad. Advantages claimed for study abroad are generally based on years' worth of anecdotal reports about what students gain from being abroad and to what these gains might be attributed.

Prominent among these beliefs is the assumption that students studying abroad are "immersed" in the native speech community and that their exposure to the presumably rich linguistic environment is responsible for potential gains in their use of the target language. Beyond assumptions, there is also some accumulated evidence to support these beliefs. For example, there is an influential early report by John Carroll (1967) based exclusively on the results of multiple choice test scores. There is also a handful of more recent studies, based either on test scores alone or on student self-reports, and multi-institution, multi-year studies conducted by Brecht and his colleagues (1991, 1995), on the acquisition of Russian by study abroad students. In addition, several studies which compare the language learning of students in study abroad contexts with those in the regular classroom have 
demonstrated increased gains in vocabulary (DeKeyser 1986, 1991; Lennon 1990; Milton \& Meara 1995; Walsh 1994), in the acquisition of sociolinguistic features of the language (Lafford 1995; Marriott 1995; Regan 1995), and in expression of oral fluency (Freed 1995b, Lafford 1995). By contrast, there has been little support for overall improved grammatical control on the part of students who have been abroad as compared to those whose learning is limited to the At Home classroom (Freed 1995b, Möhle, 1984; Möhle \& Raupach, 1983; Regan, 1995). While a few studies have, in fact, demonstrated gain for isolated syntactic features for Study Abroad students, most of these studies track changes in the use of specific grammatical features by Study Abroad students but they do not provide comparative data for students at home (Howard 2001, Isabelli 2002, Lennon 1990).

Of particular interest in the general literature on the nature of gains in the Study Abroad context are studies which suggest that the overall experience has taken on certain mythic proportions. Some recent work has suggested that students are not necessarily "immersed" in the native speech community, that homestay experiences are not necessarily preferable to other living arrangements, that some students do not use the target language as much as has been believed nor do they consistently avail themselves of the numerous opportunities to participate in the native culture as we may have expected (Frank, 1997; Pellegrino, 1998; Wilkinson, 1995).

In addition to studies that have focused on comparisons of language learning in the study abroad as compared to the home language classroom, several scholars have also attempted to identify predictors of gain abroad. In particular, work by Brecht et al. (1995) has strongly suggested that students with greater grammatical skill (as measured by SAT-like tests) prior to going abroad are likely to make greatest gains in oral performance.

Against this background, our team mounted a multi-pronged effort to look at gains in oral skills over the course of one semester by two groups of students, one studying at home and the other abroad. Our goal in this paper is to present the main themes that emerged from that larger study (reported more fully in Collentine \& Freed, 2004) in order to raise questions about their implications for study abroad programs.

The research was organized into eight research topics emanating from the three overarching questions listed above. These touched on the following potential differences between Study Abroad and At Home learning contexts: Differences in (1) gains in oral proficiency and oral fluency; (2) the acquisition of vocabulary and grammatical control; (3) communication strategies used; (4) pronunciation gains; (5) the way cognitive processing abilities related to oral performance gains; and (6) the role played by extracurricular time-on-task factors in determining gains. Finally, regarding Study Abroad, we also attempted to learn whether (7) there were specific environmental factors affecting language gain, such as contact with the homestay family and other forms of out-of-class contact with native speakers, and whether (8) there was any form 
of preparation (e.g., prior levels of grammatical achievement) that predicted gains. Below we present the general methodology used in this study and the results in broad outline form.

\section{M e t h o d}

\section{Participants}

Forty-six (46) students ( $M=22$ years; 36 females, 10 males) studying Spanish as a second language constituted the population for the study. Criteria for participation included: English as their first language; formal study of Spanish for at least 2 semesters; no prior experience studying Spanish abroad; non-Heritage language speakers; and no Spanish spoken in their home. Data were included only from participants completing all questionnaires, tests and interviews. Thus, for some analyses the sample size dropped to 40 .

There were 20 students in the At Home setting, studying at their home university, at the University of Colorado (Boulder), in the United States. These students were enrolled in only one Spanish language-learning class per week focusing on reading, writing, and speaking skills (typically 3-5 hours per week). The Study Abroad group consisted of 26 U.S. students (primarily from the University of Colorado), who were commencing a study abroad semester at the Universidad de Alicante in Spain sponsored by the Council on International Educational Exchange. These students were enrolled in about 17 hours of classes per week covering Spanish language grammar and syntax, reading and writing, conversation and Spanish society and culture.

Testing instruments included questionnaires, interviews and computer-based tasks. These were administered at the beginning of the semester and again at the end of the semester, 13 weeks later. These instruments and the measures they yielded are briefly described below.

\section{Question a ires}

To gather information about various aspects of students' language history and use of Spanish during the semester, we administered a detailed language history/ language use questionnaire known as the Language Contact Profile (Freed, Dewey, Segalowitz, \& Halter, 2004) to all students at the beginning and end of the semester (that is, pre-test and post-test). The 4-page pre-test and 6-8-page post-test Language Contact Profile were given in English, appropriately modified for the At Home and Study Abroad contexts. Each language contact question asked students to indicate how many days per week and how many hours per day they engaged in each of the four basic language skill activities—speaking, reading, writing, listening-outside class. 
For the Study Abroad group we also obtained a separate measure of time spent with the home-stay family. Students recorded their current Spanish language courses, providing information about classroom-based language contact.

\section{Intervie w s}

The ACTFL/ETS Oral Proficiency Interview (OPI) was used to gather a pre- and post-test corpus of oral data (Breiner-Sanders, Lowe, Miles, \& Swender, 2000). This provided an index of oral proficiency on a well-established scale ranging from novice through intermediate to advanced, with low, mid, and high levels for each. This interview was conducted at the beginning of the semester (pre-test) and again at the end of the semester (post-test). The interviews lasted approximately 20-30 minutes.

\section{O r a I F I u e n c y}

A 2-minute extract of student speech was taken from the OPI at minute 7 and another 2-minute extract was taken at minute 12 of the interview. Thus four samples of student speech-four minutes from the pretest OPI and four minutes from the posttest OPI-were transcribed to paper and digitized for timing analyses that yielded measures of oral fluency, including speech rate, presence of silent pauses of $400 \mathrm{~ms}$ or longer, and presence of filled pauses (such as 'ah', 'um', 'uh').

\section{Com mu ication Strategies}

The interview data yielded examples of how the students handled situations where communication "breakdowns" or gaps emerged in the conversation with the interviewer. The communicative techniques the students used to deal with these situations were classified into categories that reflected various possible strategies for handling such gaps. The need to use such strategies was expected to decrease with increasing proficiency since we expected the more advanced students to experience fewer communication gaps.

\section{Pron unciation}

We also administered a short read-aloud text at pre-test and again at post-test. The text contained 60 target words designed to elicit speech samples on specific phonological targets typically considered to be markers of English speakers' accent in Spanish (e.g., word-initial stops, intervocalic fricatives, word-final laterals, and palatal nasals).

\section{Vocabulary and Grammatical Skills}

We administered the SAT II Spanish Test (the version excluding the listening portion) to all students in both contexts of learning. This test included 88 multiplechoice items and was given at the beginning of the semester only. The SAT scores 
provided a measure of the students' general grammatical knowledge at the beginning of the research period, allowing us to approximate from norms their initial levels of knowledge of the language. The eight minutes of oral speech from the OPI data provided speech samples from which it was possible to analyze specific features of the students' grammatical abilities, vocabulary knowledge and changes in these abilities over the course of the semester. These analyses examined 17 measures of morphological, syntactic, and morphosyntactic structures at pre-test and post-test, including for example, copula accuracy (ser or estar), preposition accuracy, object-pronoun accuracy, coordinate-conjunction accuracy, subordinate-conjunction accuracy, and subordinateclause count, among others.

\section{Computer-based T a s k s}

Finally, a set of computer-based cognitive tests was included in the battery of assessment materials. These tasks yielded reaction time measures reflecting speed and efficiency of visual word recognition or lexical access (ability to recognize the meaning of a word presented in written form) and language-related attention focusing skills (ability to shift focus of attention from one language-relevant dimension to another).

In the word recognition test, the students saw a word appear on the computer screen (e.g., DOG) and they had to judge whether it referred to a living or nonliving object by pressing one of two reaction time buttons as quickly as possible. This test was conducted in separate blocks of 100 trials in English and in Spanish.

In the attention-focusing test, there were blocks of attention Shift trials and Noshift trials in each language. The stimulus words used for these trials were 20 very well known words drawn from five categories as follows: WHERE? above, inside, near, under; WHOM? her, him, them, you; WHEN? never, soon, tomorrow, yesterday; HOW MANY? few, many, several, some; TO BE: are, is, was, were, with corresponding sets in Spanish. These words and their category membership were studied at the beginning of the test session. On No-shift trials, the participants saw a category name and three words, each from a different category. Participants had to press one of three reaction time buttons corresponding to the screen location of the three words (left, middle, right) to indicate which word belonged the category named at the bottom of the screen. The same category name was repeated for a run of trials before a new run was begun with a different category name. On Shift trials, participants saw three words on the screen (and no category name). On the first Shift trial they had to choose any word by pressing the button corresponding to its location. On the next trial they saw three new words and they had to now shift categories by selecting a word that belonged to a different category from the one they had previously chosen. They continued in this manner, continuously shifting by choosing a word that differed from the category to which the 
word selected on the previous trial belonged. The difference between performance on the Shift trials and No-shift trials provided a measure of the participants' attention focusing ability (the smaller the difference, the greater the ability).

The measures yielded by these cognitive tests were reaction time, indicating speed of processing, and variability of reaction time (intra-individual coefficient of variability), indicating efficiency of processing which has been related to automaticity (Segalowitz \& Segalowitz, 1993). Measures of lexical access and attention-focusing ability specific to second language processing were obtained by statistically partialling out performance in English from performance in Spanish. In this way we controlled for individual differences in task performance that was not related to language as such (e.g., motor skills, motivation, general intelligence) and for individual differences in general lexical access and attention focusing ability that would apply to English as well as Spanish. These cognitive measures tapped language processing abilities that may be expected to change with experience, rather than reflecting more permanent language aptitude traits.

\section{R e s u I t s}

Our major findings are summarized below in terms of the three main questions listed above regarding differences between Study Abroad and At Home learning contexts. Full statistical details for the results reported below, including corrections for multiple testing, can be found in the papers cited.

\section{Linguistic G a ins}

How did the learners in the two contexts compare with respect to the linguistic gains they made? We offer a summary here of the gains made by students in overall oral proficiency, in oral fluency, and in pronunciation, vocabulary and grammatical knowledge.

\section{Gains in oral proficiency and oral fluency}

Initial analyses showed that the Study Abroad and the At Home groups did not differ at the time of pretest on the oral proficiency and oral fluency measures discussed below. Overall, the Study Abroad group showed gains whereas the At Home group did not. First, as measured by the OPI, Study Abroad students demonstrated greater gains in oral proficiency than did At Home students on this holistic measure of oral ability. Overall, gains were modest but statistically significant, reflecting an increase of about one level (i.e., a gain from intermediate-low to intermediate-mid). A statistically significant majority of students in the Study Abroad group gained in oral proficiency (12 out of 22), $(p<.001$, Sign Test) while only a minority did so in the At Home group (5 out of 18, 
n.s. $)(N=40$ here because 6 did not complete all tests $)$. Second, only the Study Abroad students made gains as a group in oral fluency. This can be seen in Table 1 below, where results are shown as effect sizes (the difference between posttest and pretest divided by the standard deviation of the pretest scores). The Table shows that the Study Abroad group made gains in the majority of the oral fluency measures - rate of speech, mean length of utterance without fillers, and length of longest utterance without hesitations or fillerswhereas the At Home group did not make significant gains. All these results suggest that the Study Abroad group made important gains in both oral proficiency and oral fluency gains in Spanish during the one semester abroad in contrast to the At Home group. Gains were seen especially in terms of increased fluidity in speech defined in terms of absence of both filled pauses and silent pauses that were unusually long as well as in terms of their rate of speech (temporal phenomena).

\section{Table 1: Pre-test to Post-test change in measures of oral fluency, At Home and Study Abroad groups}

\begin{tabular}{cc} 
& \multicolumn{1}{c}{$\begin{array}{c}\text { Effect size* of change } \\
\text { from Pre-test to Post-test }\end{array}$} \\
\cline { 2 - 3 } Context & At Home Study Abroad
\end{tabular}

$$
(\mathrm{n}=18) \quad(\mathrm{n}=22)
$$

\begin{tabular}{lrr}
\hline Measure of Oral Fluency & & \\
Rate of Speech & +0.08 & +3.37 \\
Mean length of hesitation-free runs & -0.31 & -0.02 \\
Mean length of filler-free runs & +0.38 & +0.89 \\
Longest fluent run (free of hesitations and/or fillers) & -0.15 & +0.72 \\
\hline
\end{tabular}

* Positive effect size changes indicate better performance (faster speech rate, longer utterances).

\section{Grammatical abilities and vocabulary}

Analyses of the recorded speech samples suggested that the Study Abroad experience did not result in overall improved grammatical abilities. As reported in Collentine (2004), the At Home group, if anything, showed superior gains in grammatical performance. These gains were related largely to those aspects of grammar that are particularly stressed in the Spanish classroom learning, in particular the learning of verb morphology and subordinate conjunctions (vis-à-vis the emphasis on mood selection accuracy in these syntactic environments). However, the Study Abroad students demonstrated an increased ability to generate more instances of narrative discourse than did At Home students. That is, they were better at concatenating subordinate clauses and using words that were informationally rich (nouns, attributive adjectives and multisyllabic words). Using five variables that Biber (1988) identified as those most frequently associated with narrative discourse-past tense-verbs, third-person morphology, past participles, present parti- 
ciples, and verbs of communication and events-Collentine computed narrative scores by summing each student's use of these variables at the time of pretest and posttest. As can be seen in Table 2, the Study Abroad students made greater gains in this ability than did the At Home students. Collentine also reported that narrative scores did not correlate with speech rate measures of fluency, indicating that the increased narrative scores of the Study Abroad students cannot be attributed solely to their increased oral fluency. For fuller details of the grammatical and vocabulary analyses, see Collentine (2004).

\section{Pronunciation}

\section{Table 2: Pre-test to Post-Test change in measures of narrative ability}

\begin{tabular}{|c|c|c|}
\hline & \multirow[b]{2}{*}{ Context } & $\begin{array}{l}\text { Effect size* of change } \\
\text { from Pre-test to Post-test }\end{array}$ \\
\hline & & $\begin{array}{cc}\text { At Home } & \text { Study Abroad } \\
(\mathrm{n}=20) & (\mathrm{n}=26)\end{array}$ \\
\hline Narrative Score & & +0.59 \\
\hline
\end{tabular}

*Positive effect size changes indicate better performance (faster speech rate, longer utterances).

The Study Abroad students did not, in general, demonstrate greater gains than the At Home group in terms of increased native-like pronunciation of the targets that were included in this study. Overall, learners in both groups showed gains in the pronunciation of some targets (e.g., in voiceless initial stops and word-final laterals) and not in others (e.g., intervocalic fricatives) over the one semester that testing took place. There was no obvious advantage to the Study Abroad group. For fuller details of the analyses of the read-aloud/pronunciation test, see Díaz-Campos (2004) and DíazCampos and Lazar (2003).

\section{Communication strategies}

Overall, the students in this study were found to use 26 different communication strategies. However, the vast majority of communication strategies were confined to just a few of these. Among the more frequently used strategies were those that involved self-repair and accuracy checks on the learner's own speech, and restructuring. At the beginning of the semester, the mean number of tokens of such communicative strategy use was 44.80 per 500 words of speech for the At Home group and 33.96 per 500 words of speech for the Study Abroad group (by the end of the semester, the corresponding means were 32.35 and 15.35). These communication strategies can be classified in various ways according to their nature. Table 3 
shows the mean total number of communication strategies used at the end of the semester by students in the At Home and the Study Abroad groups and the mean number as a function of language (first versus second language based), type (direct strategies involving intentional reformulation to get the meaning across versus interactional strategies involving cooperative exchanges with the interlocutor such as requests for clarification), and source (resource deficit reflecting a lack of knowledge, other performance reflecting a problem perceived in the interlocutor's speech, or a focus on the learner's own performance). In every case, the Study Abroad group used significantly fewer communication strategies at the end of the semester than did the At Home group, as was borne out by analyses in which performance at pre-test was covaried out from performance at post-test. For fuller details of the analyses of the communication strategies, see Lafford (2004).

Table 3: Post-test use of communication strategies (normalized over 500 words)

\begin{tabular}{lcc} 
& $\begin{array}{c}\text { Context } \\
\text { At Home } \\
(\mathrm{n}=18)\end{array}$ & $\begin{array}{c}\text { Study Abroad } \\
(\mathrm{n}=26)\end{array}$ \\
\hline $\begin{array}{l}\text { Overall use of communication strategies } \\
\text { Communication strategies grouped by: }\end{array}$ & 32.35 & 15.35 \\
$\quad$ Language & & \\
$\quad$ First language-based (English) & 3.81 & 0.78 \\
$\quad$ Second language-based (Spanish) & 28.51 & 14.52 \\
Type & & \\
$\quad$ Direct & 28.04 & 10.75 \\
$\quad$ Interactional & 9.28 & 4.55 \\
Source & & \\
$\quad$ Resource Deficit & 9.28 & 3.68 \\
$\quad$ Own accuracy check & 2.78 & 0.95 \\
$\quad$ Focus on own performance & 19.42 & 10.66 \\
\hline$\quad$
\end{tabular}

\section{Predictors of Language Gains}

Beyond the question of whether differential linguistic gains were made by students in the two learning contexts, we were also interested in identifying factors that might predict such gains. The following three categories of predictors were examined: (a) Cognitive processing abilities (speed and efficiency of lexical access and attention control); (b) Time-on-task measures, including time reported spent using the target language out of class; and (c) Prior experience learning Spanish and prior knowledge of the language at the time of pre-test. In our study we were able to identify pretest variables that were significantly associated with, and in this sense predicted, post-test outcomes; however, it is not possible to establish causal relationships by means of such correlational analyses alone (see Lazar, 2004, for discussion of this issue). 


\section{Cognitive processing abilities}

Several interesting results emerged from the analyses of the cognitive variables. First, the measures of speed of visual word recognition (lexical access) and efficiency of visual word recognition (automaticity) correlated significantly with oral fluency in terms of mean run length free of filled pauses $(r>.37$ in each case, $p<$ $.05)$. It is important to note here that for these correlations the measures of second language visual word recognition were obtained by first partialling out performance in first language visual word recognition. This means that the relationships obtained in this study between oral fluency and cognitive processing measures were specific to the participants' functioning in the second language rather than due to trait characteristics of the learners (such as their general ability to access meaning, regardless of language). These results confirmed that speed (based on reaction time of task performance) and efficiency (based on intra-individual variability in speed of performance) of word recognition are important components of oral fluency. Also, as can be seen in Table 4 below, learners in both groups made significant gains in speed and efficiency of second language word recognition from pre-test to post-test. There were no significant differences between the groups in the size of these gains (effect sizes for these gains in the second language ranged from +0.87 to +1.40 ) . Finally, to see if initial levels of cognitive processing were related in any way to gains in oral proficiency (OPI), the second language-specific measures of lexical access speed and efficiency were submitted to analysis of variance with the between group factors being Context (At Home, Study Abroad) and Oral Gain (Gain, No gain) (gain here was defined as obtaining a higher OPI rating at post-test compared to pre-test). These analyses yielded significant main effects indicating that students

\section{Table 4: Pre-test to Post-test change in speed and efficiency of visual word recognition}

\begin{tabular}{|c|c|c|c|}
\hline & \multirow[b]{2}{*}{ Context } & \multicolumn{2}{|c|}{$\begin{array}{l}\text { Effect size* of change } \\
\text { from Pre-test to Post-test }\end{array}$} \\
\hline & & $\begin{array}{l}\text { At Home } \\
(\mathrm{n}=18)\end{array}$ & $\begin{array}{l}\text { Study Abroad } \\
\qquad(\mathrm{n}=22)\end{array}$ \\
\hline \multicolumn{4}{|l|}{ First Language (English) } \\
\hline Speed of visual word recognition & & +0.52 & +0.68 \\
\hline Efficiency of visual word recognition & & +0.27 & +0.49 \\
\hline \multicolumn{4}{|l|}{ Second Language (Spanish) } \\
\hline Speed of visual word recognition & & +0.87 & +0.90 \\
\hline Efficiency of visual word recognition & & +1.40 & +1.12 \\
\hline
\end{tabular}

* Positive effect size changes indicate better performance (faster, more efficient). 
who made oral gains had started out with superior lexical access abilities in the second language. There were no significant effects related to context of learning. The Gain group result is consistent with the idea that perhaps some initial threshold level of basic word recognition processing abilities are necessary for oral proficiency and oral fluency to develop.

Gains in attention control did not correlate significantly with any of the measures of oral fluency. However, one interesting result was that, for the whole sample ( $n$ $=40$ ), post-test efficiency of attention control (where efficient attention control is reflected in intra-individual low reaction time variability on the attention shift test) was correlated significantly and negatively with post-test rate of $\operatorname{speech}(r=-.476, n=$ 40). The attention measure here was obtained by partialling out attention performance in the first language, so this variable reflected abilities specific to the learners' second language skills and not general trait abilities to control attention. This result indicated that at the end of the semester the greater a learner's efficiency in shifting attention, the slower that person's rate of speech.

\section{Time-on-task}

Analyses were conducted on time-on-task as reflected in reported number of hours per week spent engaged in extracurricular activities in the four skill areasspeaking, reading, writing, and listening. None of the correlations between reported amount of activity using Spanish outside of class with gains in oral fluency and gains in the OPI measure of oral proficiency were significant. Overall, these results suggested that time-on-task considerations did not play a major role in the superior gains in oral proficiency and fluency by the Study Abroad students. However, Lafford (2004) found a significant negative correlation between time-on-task and the use of communication strategies by the Study Abroad group.

\section{Prior knowledge and experience learning Spanish}

Finally, we examined whether measures of prior knowledge and/or experience in learning Spanish predicted fluency gains. The results of the Spanish grammar SAT indicated at the time of pre-test, the At Home group obtained a mean SAT score of 513 placing them, according to norms, at the beginning of a third semester university-level Spanish course in the United States whereas the Study Abroad Group obtained a mean score of 442, placing them slightly before the middle of the second semester in ability level. This initial difference favoring the At Home group was statistically significant. Despite this difference, neither the pre-test grammar SAT scores nor years of previous study of Spanish correlated significantly with language gains. 


\section{Special Characteristics of the $S t u d y$ A b r o a d C o n t e xt}

Additional analyses were conducted with the data from the Study Abroad group to see if the environmental characteristics available in the context - home stay opportunities, exposure to Spanish outside of class - conferred any advantages to the students. Only the following statistically significant patterns were found. As reported in Lafford (2004), the use of communication strategies correlated significantly and negatively with the amount of time Study Abroad students reported using Spanish outside the classroom $(r=-.760, p<.001)$ and with the amount of time they reported speaking with their host families in the home stay environment $(r=-.469, p=.016)$, indicating that the more students took advantage of these features of the learning context, the less they had to rely on communication strategies to handle information gaps. These results also support the idea that the more students communicated on a regular basis with native speakers, the more they became attuned to the pragmatic demands of a communicative context, which may have decreased the likelihood of communication gaps and hence the need to resort to communication strategies (Lafford, 2004).

Analysis of how the cognitive variables related to reported language use in the Study Abroad setting also yielded an interesting result. In the Study Abroad group, gains in speed of attention control correlated significantly and negatively $(r=-.523, \mathrm{n}$ $=19$ ) with reported amount of language contact with the home stay family. This result indicates that the more students reported speaking with the host family the less they developed attention control in Spanish.

\section{Discussion}

The general findings of the various parts of this complex study may be summarized as follows. First, students who spent a semester studying in Spain were found to have made greater gains in oral proficiency and in several aspects of oral fluency compared to those who studied at their home university in the United States. Interestingly, however, these results could not be attributed simply to the fact that the students in Spain spent a greater amount of time out of class using Spanish, as reflected in the fact that variables related to self-reported time-on-task did not correlate positively with gains.

Second, the study abroad students appeared to have developed superior narrative discourse abilities. They also learned how to maintain a conversation with native speakers with less frequent need to resort to communication strategies to compensate for linguistic gaps in their conversation. In these respects, the findings are consistent with the anecdotal, and sometimes documented, experiences of other Study Abroad students. These results help to explain why it is commonly believed that students who go abroad make greater progress than their peers at home - quite simply "they sound 
better." The gains in reducing dependence on communication strategies appeared to be directly related to the degree to which students took advantage of the special opportunities afforded by the study abroad setting to speak with native speakers of Spanish. What might also contribute to this finding is that Study Abroad learners return producing more 'lexically dense' words (e.g., nouns, attributive adjectives) in a given sentence/phrase than their At Home counterparts.

Third, when discrete features of the language of these Study Abroad students were analyzed, we found that in certain areas they did not make significantly greater gains than their peers at home. In fact, analyses done at the end of the semester revealed that sometimes their abilities were markedly less than those of the At Home students. For example, in their control of numerous aspects of Spanish grammar, the Study Abroad students' skills often declined in the course of the semester when compared with At Home students. Indeed, the major differences between the two groups related precisely to those grammatical aspects that Spanish formal instruction emphasizes (with the At Home students performing better). Moreover, pronunciation of selected features of Spanish phonology was not more accurate for Study Abroad students than for At Home students.

Fourth, there emerged some complex relationships involving some of the cognitive variables. We found, for example, that students who made gains in oral proficiency started out with significantly faster and cognitively more efficient second-languagespecific abilities in word recognition, suggestive of a cognitive threshold for second language learning readiness. We also found that, for the Study Abroad group, gains in speed of attention control (gains in how fast the learner could shift focus of attention) correlated negatively with the reported amount of contact with the home stay family. This was perhaps our most surprising finding. Such a result could reflect the possibility that conversations in the home stay context tended to be brief and formulaic (restricted to greetings, simple chitchat, etc.). If this were the case as some have suggested (Frank, 1997; Wilkinson, 1998), students may not have been challenged to develop attentionrelated skills as they might otherwise have been.

In interpreting these results, we suggest the possibility of a consideration that has, as yet, been unexplored within the field of second language acquisition. The more the adult learner is able to communicate in the target language the more he or she will do so. As a result, the very act of communicating will further enhance learning, leading to more communication, which should promote further learning. This feedback effect is sometimes referred to as reciprocal causation, where the results of learning lead to consequences affecting the course of learning itself. The feedback loop can, however, be negative as well. Such negative effects (known in the child reading acquisition literature as Matthew Effects; Stanovich, 1986; 2000) occur when the learner is unable 
to gain sufficient momentum in his or her learning to support engaging in the very activities that are necessary to promote further learning. It may be that in the early stages of learning some second language learners lack threshold levels of certain cognitive or linguistic abilities or fail to develop them through experience (e.g., sufficiently rapid or automatic word recognition or attention control abilities, as seen in this study). Such learners may become overwhelmed and/or discouraged at later stages when they cannot meet the cognitive and linguistic demands of communicating in more natural and complex situations. This might decrease motivation to communicate with other speakers of the language, resulting in a process that limits continued learning (the negative feedback loop).

In conclusion, our results indicate that when thinking about what effects study abroad (or any particular learning context, for that matter) might have on second language learning, it is very important to consider more than whether students make greater gains in one environment than in another. Researchers need to look beyond simple quantitative issues such as how much exposure to the target language students have or what level of language ability they bring with them to the learning situation. We need to more fully explore some of the qualitative aspects of learning afforded by a particular context. This means looking at the nature of the communicative interactions available to the learner and actually entered into, taking into account all communicative opportunities, including what transpires inside, as well as outside, the classroom. The act of communicating may itself enhance learning through positive feedback that not only provides new input (for example, new vocabulary) or confirmatory or corrective feedback, but also strengthens the cognitive underpinnings of fluency development, leading to faster and more efficient processing that in turn renders learning even more effective. It is, therefore, equally important to consider the nature of the learner's language learning readiness in terms of underlying processes that support oral fluency. We need to ask in what ways the learner is prepared for the special challenges presented by a specific learning context. We also need to consider how those things a student brings to a learning environment change as a function of the experiences afforded by that learning environment. These are crucial and complex questions because they involve interactions between multiple characteristics of the context and of the learner. Such complex feedback processes make it unlikely that there will be a simple, direct relationship between amount of exposure to the language and linguistic development, as indeed was found to be the case in the study reported here. As we gain more knowledge about the dynamic of these complex interactions, it should become easier to make appropriate fits between learners and learning contexts, and to better understand the potential influence of one context of learning compared to another on second language acquisition success. 


\section{Not e}

This research was funded in part by a grant to Barbara Freed (from the Council on International Educational Exchange), and in part by grants to Norman Segalowitz (from the Natural Sciences and Engineering Research Council of Canada, and from the Dean's Office, Faculty of Arts and Science at Concordia University).

\section{Refere nce $s$}

Biber, D. (1988). Variation across speech and writing. New York: Cambridge University Press.

Brecht, R. D., Davidson, D. E., \& Ginsberg, R., B. (1995). Predictors of Foreign Language Gain During Study Abroad. In B. Freed (Ed.), Second Language Acquisition in a Study Abroad Context (pp. 37-66). Amsterdam: John Benjamins.

Brecht, R. D., \& Robinson, J. L. (1995). On the value of formal instruction in study abroad: Student reactions in context. In B. F. Freed (Ed.), Second Language Acquisition in a Study Abroad Context (pp. 317-333). Amsterdam: John Benjamins.

Breiner-Sanders, K., Lowe, P., Miles, J., \& Swender, E. (2000). ACTFL proficiency guidelines: Speaking, revised 1999. Foreign Language Annals, 33, 13-18.

Carroll, J.B. (1967). Foreign Language Proficiency Levels Attained by Language Majors Near Graduation From College. Foreign Language Annals, 1, 131-151.

Coleman, J. (1998, Fall). Language learning and study abroad: The European perspective. Frontiers, 167-203.

Collentine, J. (2004). The effects of learning contexts on morphosyntactic and lexical development. Studies in Second Language Acquisition, 26, 229-250.

Collentine, J. \& Freed, B. (Eds.) (2004). Learning context and its effects on second language acquisition. Thematic issue of Studies in Second Language Acquisition, 26.

DeKeyser, R. (1986). From learning to acquisition? Foreign language development in a US classroom and during a semester abroad. Unpublished doctoral dissertation, Stanford University.

DeKeyser, R. M. (1991). Foreign language development during a semester abroad. In B. Freed (Ed.), Foreign Language Acquisition and the Classroom (pp. 104-118). Lexington, MA: D.C. Heath and Company.

Díaz-Campos, M. (2004). Context of learning in the acquisition of Spanish second language phonology. Studies in Second Language Acquisition, 26, 249-273.

Díaz-Campos, M., \& Lazar, N. (2003). Acoustic analysis of voiceless initial stops in the speech of Study Abroad and Regular Class students: Context of learning as a variable in Spanish second language acquisition. In P. Kempchinsky and C.-E. Piñeros, (Eds.), Theory, practice, and acquisition: Papers from the 6th Hispanic Lin- 
guistics Symposium and the 5th Conference on the Acquisition of Spanish and Portuguese (pp. 352-370). Somerville: Cascadilla Press.

Frank, V. (1997, March). Potential negative effects of homestay. Middle Atlantic Conference of the American Association for the Advancement of Slavic Studies, Albany, NY.

Freed, B. (1995a). Second language acquisition in a study abroad context. Amsterdam: John Benjamins.

Freed, B. (1995b). What makes us think that students who study abroad become fluent? In B. Freed (Ed.), Second language acquisition in a study abroad context. (pp. 123-148). Amsterdam: John Benjamins.

Freed, B. (1998). An overview of issues and research in language learning in a study abroad setting. Frontiers, 31- 60 .

Freed, B. F., Dewey, D. P., Segalowitz, N. S., \& Halter, R. H. (2004). The language contact profile. Studies in Second Language Acquisition, 26 (2), 349-356.

Freed, B., Segalowitz, N., \& Dewey, D. (2004). Context of learning and second language fluency in French: Comparing regular classroom, study abroad, and intensive domestic immersion programs.. Studies in Second Language Acquisition, 26 (2) 275-301.

Howard, M. (2001). The effects of study abroad on the 12 learner's structural skills: Evidence from advanced learners of French. EUROSLA Yearbook, 1, 123-141.

Isabelli, C. (2002). The impact of a study-abroad experience on the acquisition of L2 Spanish Syntax: The null subject parameter. Unpublished doctoral dissertation, University of Illinois-Champaign.

Lafford, B. (1995). Getting into, through and out of a survival situation: A Comparison of communicative strategies used by students studying Spanish Abroad and 'At Home'. In B. F. Freed (Ed.), Second language acquisition in a study abroad context (pp. 97-121). Amsterdam: John Benjamins.

Lafford, B. (2004). The effect of the context of learning on the use of communication strategies by learners of Spanish as a second language. Studies in Second Language Acquisition, 26, 201-225.

Lazar, N. (2004). A short survey on causal inference, with implications for context of learning studies of second language acquisition. Studies in Second Language Acquisition, 26, 329-347.

Lennon, P. (1990). Investigating fluency in EFL: A quantitative approach. Language Learning, 40, 387-417.

Marriot, H. (1995). Acquisition of politeness patterns by exchange students in Japan. In B. Freed (Ed.), Second language acquisition in a study abroad context (pp. 197224). Philadelphia: John Benjamins. 
Milton, J. \& P. Meara. (1995). How periods abroad affect vocabulary growth in a foreign language. ITL Review of Applied Linguistics, 107/108, 17-34.

Moehle, D. (1984). A comparison of the second language speech of different native speakers. In H. Dechert, D. Möhle, M. \& Raupach, M. (Eds.), Second language productions (pp. 26-49). Tübingen: Narr.

Möhle, D. \& M. Raupach. (1983). Planen in der Fremdsprach. Frankfurt: Peter Lang.

Pellegrino, V. (1998, Fall). Student perspectives on language learning in a study abroad context. Frontiers, 91-120.

Regan, V. (1995). The acquisition of sociolinguistic native speech norms: Effects of a year abroad on second language learners of French. In B. Freed (Ed.), Second language acquisition in a study abroad context (pp. 245-268). Philadelphia: John Benjamins.

Segalowitz, N., \& Freed, B. F. (2004). Context, contact and cognition in oral fluency acquisition: Learning Spanish in At Home and Study Abroad contexts. Studies in Second Language Acquisition, 26, 173-199.

Segalowitz, N. S., \& Segalowitz, S. J. (1993). Skilled performance, practice, and the differentiation of speed-up from automatization effects: Evidence from second language word recognition. Applied Psycholinguistics, 14, 369-385.

Stanovich, K. E. (1986). Matthew effects in reading: Some consequences of individual differences in the acquisition of literacy. Reading Research Quarterly, 21, 360-407.

Stanovich, K. E. (2000). Progress in understanding reading: Scientific foundations and new frontiers. New York: Guilford Press.

Walsh, R. (1994). The year abroad: A linguistic challenge. Teanga 14, 48-57.

Wilkinson, S. (1998). Study abroad from the participants' perspective: A challenge to common beliefs. Foreign Language Annals, 31, 23-39. 